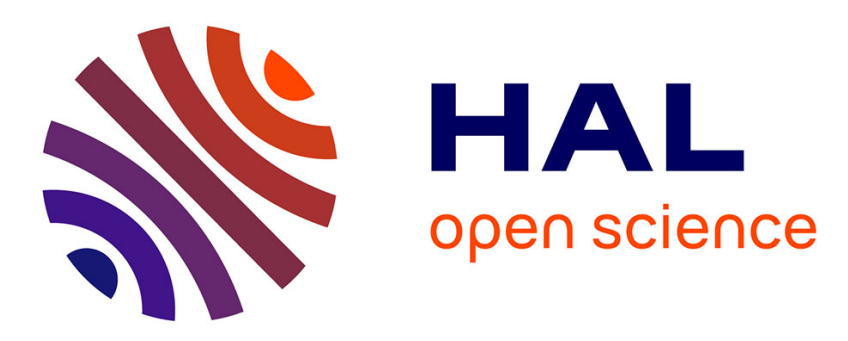

\title{
Membrane Crossing and Membranotropic Activity of Cell-Penetrating Peptides: Dangerous Liaisons?
}

\author{
Astrid Walrant, Sébastien Cardon, Fabienne Burlina, Sandrine Sagan
}

\section{To cite this version:}

Astrid Walrant, Sébastien Cardon, Fabienne Burlina, Sandrine Sagan. Membrane Crossing and Membranotropic Activity of Cell-Penetrating Peptides: Dangerous Liaisons?. Accounts of Chemical Research, In press, 10.1021/acs.accounts.7b00455 . hal-01662041

\section{HAL Id: hal-01662041 \\ https://hal.sorbonne-universite.fr/hal-01662041}

Submitted on 12 Dec 2017

HAL is a multi-disciplinary open access archive for the deposit and dissemination of scientific research documents, whether they are published or not. The documents may come from teaching and research institutions in France or abroad, or from public or private research centers.
L'archive ouverte pluridisciplinaire HAL, est destinée au dépôt et à la diffusion de documents scientifiques de niveau recherche, publiés ou non, émanant des établissements d'enseignement et de recherche français ou étrangers, des laboratoires publics ou privés. 


\title{
Membrane crossing and membranotropic activity of cell-penetrating peptides: Dangerous liaisons?
}

\author{
Astrid Walrant ${ }^{1}$, Sébastien Cardon ${ }^{1}$, Fabienne Burlina ${ }^{1}$ and Sandrine $\operatorname{Sagan}^{1}{ }^{*}$ \\ ${ }^{1}$ Sorbonne Universités, UPMC Univ. Paris 06, École normale supérieure, PSL Research University, \\ CNRS, Laboratoire des Biomolécules (LBM), 4 place Jussieu, 75005 Paris, France
}

*Corresponding author : sandrine.sagan@upmc.fr

\section{Conspectus}

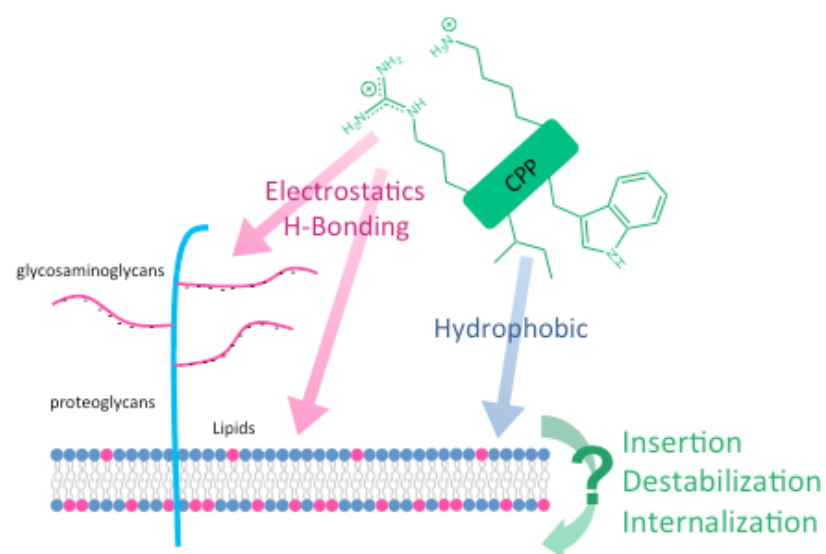

Living organisms have to maintain a stable balance in molecules and ions in the changing environment in which they are living, a process known as homeostasis. At the level of cells, the plasma membrane has a major role in homeostasis, since this hydrophobic film prevents passive diffusion of large/hydrophilic molecules between the extracellular and intracellular milieu. Living organisms have evolved with highly sophisticated transport systems to control exchanges across this barrier: import of nutrients and fuel essential for their survival; recognition of chemical or physical messengers allowing information interchanges with surrounding cells. Beside specialized proteins, endocytosis mechanisms at the level of the lipid bilayer can transport molecules from the outside across the cell membrane, in an energydependent manner.

The cell membrane is highly heterogeneous in its molecular composition (tens of different lipids, proteins, polysaccharides and combinations of these) and dynamic with bending, deformation and elastic properties that depend on the local composition of membrane domains. Many viruses, microorganisms and toxins exploit the plasma membrane to enter into cells. Chemists develop strategies to target the plasma membrane with molecules capable of circumventing this hydrophobic barrier, in particular to transport and deliver nonpermeable drugs in cells for biotechnological or pharmaceutical perspectives. Drug delivery systems are numerous and include lipid-, sugar-, protein- and peptide-based delivery systems, since these biomolecules generally have good biocompatibility, biodegradability, environmental sustainability, cost effectiveness and availability. Among those, cell-penetrating peptides (CPPs), reported for the first time in the early 1990's, are attracting major interest not only as potential drug delivery systems, but also at the level of fundamental research. It was indeed demonstrated very early that these peptides, which generally correspond to highly cationic sequences, can still cross the cell membrane at $4^{\circ} \mathrm{C}$, a temperature at which all active transport and endocytosis pathways are totally inhibited. Therefore, how these charged hydrophilic peptides cross the hydrophobic membrane barrier is of utmost interest as a pure basic and physico-chemical question.

In this Account, we focus on cationic cell-penetrating peptides (CPPs), and the way they cross cell membranes. We summarize the history of this field that emerged around 20 years ago. CPPs were indeed first identified as protein-transduction domains from the human immunodeficience virus (HIV) TAT 
protein and the Antennapedia homeoprotein, a transcription factor from Drosophila. We highlight our contribution to the elucidation of CPP internalization pathways, in particular translocation, which implies perturbation/reorganisation of the lipid bilayer, and endocytosis depending on sulfated glycosaminoglycans. We show a particular role of Trp (indole side chain) and Arg (guanidinium side chain), which are essential amino acids for CPP internalization. Interactions with the cell-surface are not only Coulombic; H-bonds and hydrophobic interactions contribute also significantly to CPP entry. The capacity of CPPs to cross cell membrane is not related to their strength of membrane binding. Finally, we present optimized methods based on mass spectrometry and fluorescence spectroscopy, that allow unequivocal quantification of CPPs inside cells or bound to the outer leaflet of the membrane, and discuss some limitations of the technique of flow cytometry that we have recently highlighted.

\section{Introduction}

A plethora of proteins have been reported for their capacity to cross cell membranes. Cellpenetrating proteins are found ubiquitously within living organisms, from viruses and bacteria, to plant and animal cells. They have very different biological functions, being detrimental when working in the context of bacterial or viral invasion of animal cells, or being crucial for the life of metazoans, as exemplified by the case of the homeoprotein transcription factors during development and adulthood of animals. Homeoproteins are of particular interest because they possess unique and unconventional cell transfer paracrine properties, being secreted by some cells and internalized into others. To understand how these proteins act to penetrate cells at the level of the plasma membrane, structure-activity relationship (SAR) studies can be done. Protein engineering and peptide synthesis indeed allow exploring protein domains that are responsible for the membrane crossing properties of these proteins.

In the early 1990s, such SAR studies led to the identification of the first protein-transduction domains (PTDs) capable to cross cell membranes: the Tat peptide (GRKKRRQRRRPQ) derived (region 4859) from the transactivator of transcription (TAT) of the human immunodeficiency virus (HIV) ${ }^{1,2}$, and the Penetratin peptide (RQIKIWFQNRRMKWKK) derived (region 341-356) from the drosophila homeoprotein Antennapedia ${ }^{3,4}$. These PTDs led to the emergence of the field of cell-penetrating peptides (CPPs), which attract much interest for therapeutical or pharmaceutical applications. CPPs were indeed early evidenced as efficient delivery systems for high molecular weight and hydrophilic molecules (oligonucleotides, proteins, antibodies etc) conjugated to their sequence ${ }^{5}$. However, beside unfavorable pharmacokinetics (mainly resulting from their rapid renal clearance), the therapeutical use of CPPs is still hampered, principally because these peptides have no cell specific entry. Some strategies have been reported to overcome this lack of specificity, but require in general hard chemistry work, a major drawback to further consider these molecules for technological or therapeutical applications. Alternatively, the emergence of cell-penetrating homing peptides is particularly promising for targeting specific cells and tissues in the context of pathologies such as cancers. These peptides indeed bind tumorspecific receptors and enhance internalization of conjugated or unconjugated payload drugs (antibodies, nanoparticles etc) through a specific bulk endocytosis (macropinocytosis-like) pathway6.

Understanding the molecular mechanisms and internalization pathways of these peptides, represents an alternative and complementary approach for the rational design of efficient CPPs with improved cell specific delivery. This review is focused on our current view of the molecular mechanisms and internalization pathways of CPPs, with a particular emphasis on their detection and quantification inside cells in relation with their membranotropic activities.

The first reported CPP sequences, Tat and Penetratin, are highly cationic peptides with an average charge of +0.67 and +0.44 per amino acid, respectively. This common feature led to the general idea that cell-penetrating peptides are only cationic sequences. However, tens of new CPPs have now been described, among which some are negatively charged and/or amphipathic ${ }^{5}$. In principle, the two peptide sequences, Tat and Penetratin, should be synthesized with blocked $N$ - and $C$-terminal ends, to mimic the peptide sequence as it is in the original protein. In addition to the cationic residues, the Tat peptide contains 2 polar $(2 \mathrm{Q})$ and 2 nonpolar $(\mathrm{G}, \mathrm{P})$ uncharged amino acids. The Tat peptide is a pure basic sequence unstructured in solution or in interaction with phospholipids or GAGs ${ }^{7}, 8$. In the context of the full TAT protein, this sequence also shows high conformational variability in its secondary structure ${ }^{9}$. On its side, the Penetratin sequence includes 3 polar $(2 \mathrm{Q}, \mathrm{N})$ and 6 nonpolar (2 I, $2 \mathrm{~W}, \mathrm{M}, \mathrm{F})$ uncharged amino acids. This peptide is a secondary amphipathic peptide when structured as a $\alpha$-helix. Penetratin free in solution has no particular secondary structure and adopts a chameleon-like structure in complex, being 
either a $\alpha$-helix or $\beta$-strand, depending on the stoechiometry and the interacting partner ${ }^{10,7,8}$. In the context of the homeoprotein, the Penetratin peptide corresponds to the highly stable third helix (without the first E residue) of the homeodomain 4 .

The amino acid composition confers to each peptide specific physico-chemical properties, which are crucial to control their interaction with cell-surface molecules and to trigger efficient entry into cells. With regard to the cell-surface, peptides first meet the glycocalyx, a thick and viscous layer of membraneinserted proteoglycans and floating polysaccharidic moieties, located on the external side of the plasma membrane. Glycosaminoglycans (GAGs) are the polysaccharide part of the proteoglycans. They are linear anionic polymers with different size and content of sulfated disaccharides, which constitute in particular chondroitin (CS) and heparan (HS) sulfates ${ }^{11}$. GAGs are highly dynamic at the cell-surface, half of these membrane-bound molecules are secreted in the cell medium, and the other half is subject to endocytotic internalization and degradation. Both processes have kinetics in the range of hours ${ }^{12}$. Below the glycocalyx, the lipid bilayer is constituted in animal cells mostly of zwitterionic phosphatidylcholine phospholipids with one cis-unsaturated fatty acyl chain, which renders them fluid at physiological temperature ${ }^{13}$. Some membrane domains are enriched in sphingomyelin and cholesterol and act as functional platforms, in which are found for instance ligand-induced clusters of syndecans ${ }^{14}$, some proteoglycans containing both anionic HS and $\mathrm{CS}^{15}$. In addition, some domains include phospholipids such as phosphatidylethanolamine (PE) that have the propensity to induce negative curvature in the membrane ${ }^{16}$. Membrane lipids are also synthesized and renewed in the time scale of few hours ${ }^{17}$.

The plasma membrane of animal cells, with its well-defined lateral and transversal supramolecular organization in relation with the molecular composition of specific domains in glycoproteins, polysaccharides and lipids, is therefore a highly complex and heterogeneous structure. In addition, the cellular environment might vary. Local changes in the membrane potential and pH modulate the physico-chemistry of the membrane, which impacts on its bending and fluidity properties. Altogether, when the question of membrane crossing of peptides and proteins is addressed, one should consider globally their chemical reactivity and physico-chemistry properties in relation with the membrane environment. For instance we identified very effective thiol-specific pathways of internalization for CPPs containing cysteine or cystine in their sequence ${ }^{18,19}$.

\section{Internalization pathways of CPPs: where do we stand?}

A general property of cell-penetrating peptides is their capacity to interact with plasma membranes. It was originally demonstrated that oligolysine were less efficiently internalized than oligoarginine peptides $20,21,22$. This finding highlighted the importance of bidentate hydrogen bonds between guanidinium groups and natural (phosphate moieties of phospholipids) or synthetic (pyrenebutyrate added to cells together with oligoarginines) counterions for crossing directly the membrane 23,24 , a process known as translocation. Translocation implies that the peptide enters directly into the cytosol of the cell (Figure 1). Bidentate hydrogen bonds of arginine with hydrophobic counterions indeed result in the partition of the ion-pair complex into the lipid bilayer and its diffusion across, likely according to the membrane potential. Other molecular mechanisms have been proposed to explain direct membrane crossing, such as the formation of transient pores ${ }^{25}$ or of inverted micelles ${ }^{26}$.

Translocation still occurs at low temperature $\left(<12^{\circ} \mathrm{C}\right)$, although with reduced efficiency because the membrane fluidity, the lipid membrane asymmetry and the membrane potential are energydependent processes. Besides, endocytosis pathways are major mechanisms reported for CPP internalization, principally through macropinocytosis ${ }^{27}$. These pathways are fully energy and temperature dependent, being inhibited at temperature below $12^{\circ} \mathrm{C}^{28}$, while the use of endocytosis inhibitors presents major drawbacks regarding cell selectivity and cytotoxicity ${ }^{29}$. Therefore, to study the respective contribution of endocytosis and translocation, we favor the use of different temperatures. 


\section{Endocytosis}

High peptide concentration

\section{Direct translocation Low and high peptide concentration}
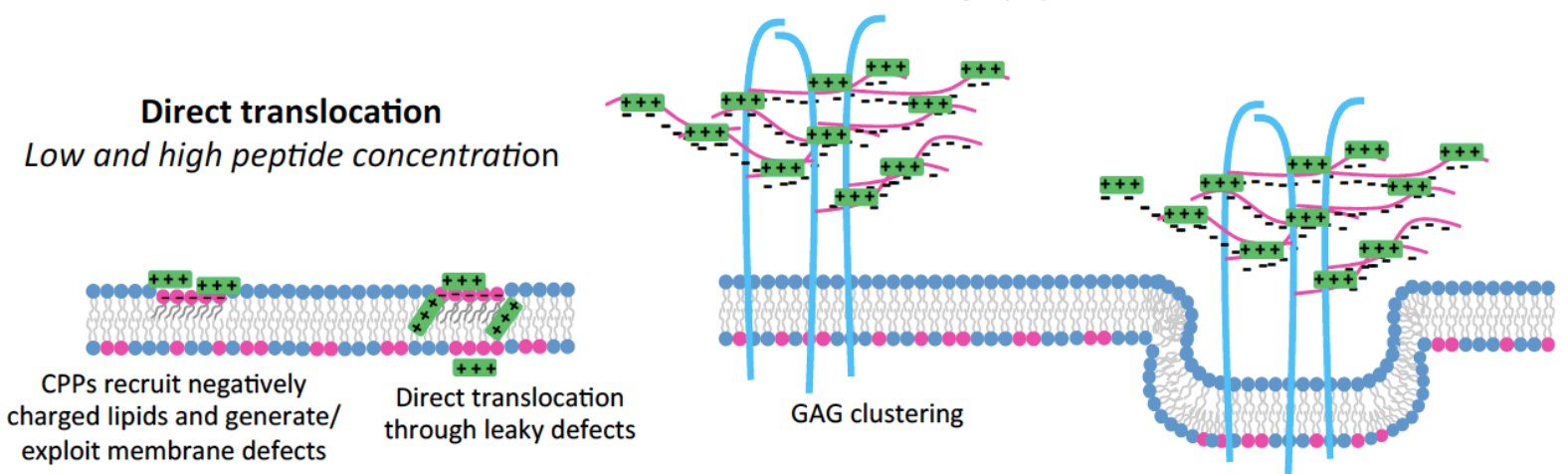

GAG-dependent endocytosis

Figure 1 - Internalization of CPPs involves two major general pathways: translocation and GAGdependent endocytosis. At low micromolar concentration, CPPs recruit negatively charged lipids and/or exploit membrane defects to translocate into cells ${ }^{50}$; They also bind sulfated GAGs of cell-surface proteoglycans. At higher micromolar concentrations, CPPs still translocate into cells, and also induce clustering of proteoglycans and endocytosis.

By quantifying the absolute amount of internalized peptide for a series of CPPs (Tat, Penetratin, R9, RW9 ...), we confirmed the crucial role of anionic GAGs in the mechanism of internalization ${ }^{30}$ (Figure 1). This result was obtained by comparing the internalization efficacy of CPPs in wild-type cells and a cell line genetically deficient in HS and CS expression ${ }^{11}$. Most CPPs we have studied had dramatic decreased internalization at $4^{\circ} \mathrm{C}$ compared to $37^{\circ} \mathrm{C}$ in WT cells ${ }^{30}$. This was not the case for GAG-deficient cells in which the CPPs had very similar internalization efficacy at both temperatures, close to the one observed in WT cells at $4^{\circ} \mathrm{C}$ (Figure 2). These results show that the endocytosis pathway of these CPPs mostly relies on the presence of GAGs at the cell-surface. Interestingly, this is not the case for Tat peptide which internalizes in similar quantities in WT and GAG-deficient cells at $37^{\circ} \mathrm{C}$ and $4^{\circ} \mathrm{C}^{30}$. Importantly, further analysis showed that at low micromolar CPP concentration $(<2-3 \mu \mathrm{M})$ and $37^{\circ} \mathrm{C}$, or any concentration up to $10 \mu \mathrm{M}$ at $4^{\circ} \mathrm{C}$, the presence/absence of cell-surface GAGs or sialic acids makes no longer differences in the internalization efficacy of different $\mathrm{CPPs}^{30-32}$ (Figure 2). These results indicate that at $37^{\circ} \mathrm{C}$ for low micromolar concentrations of peptides, only translocation occurs, while GAG-dependent internalization is a cooperative process and requires accumulation of the peptides at the cell-surface. In addition, at $4^{\circ} \mathrm{C}$, translocation is the only effective internalization pathway and is not dependent on the cell-surface composition.

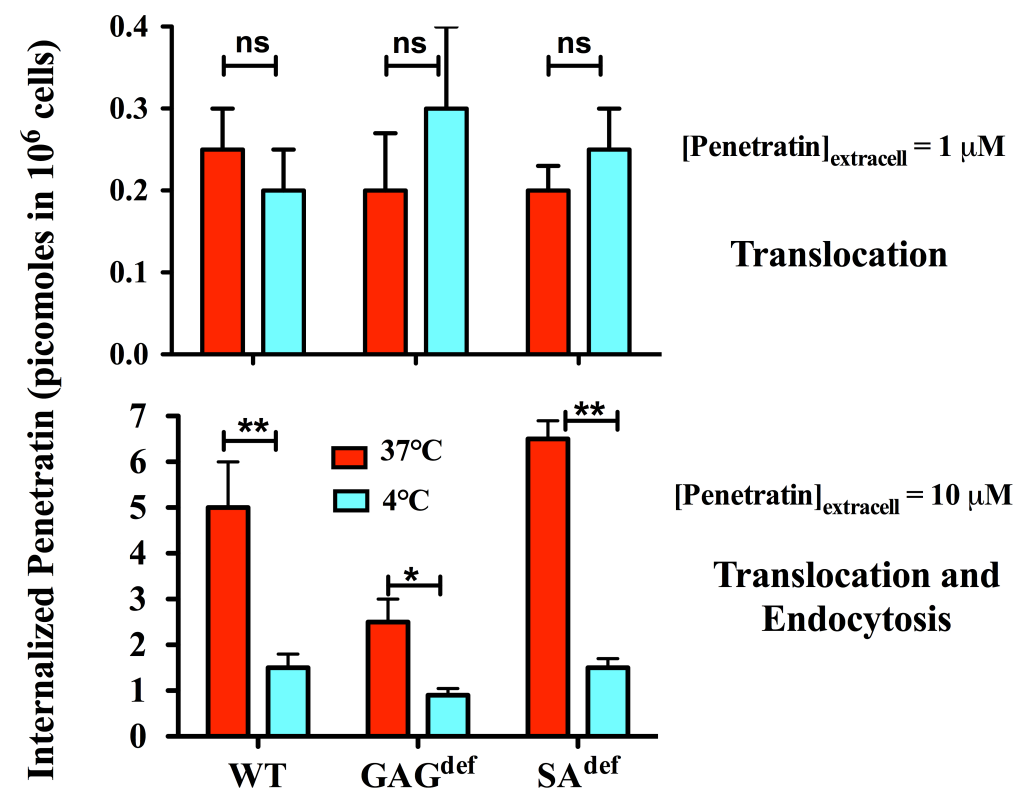


Figure 2: Translocation is observed at $1 \mu \mathrm{M}$ [Penetratin] at $37^{\circ} \mathrm{C}$ (red) and $4^{\circ} \mathrm{C}$ (blue), while at higher concentration (illustrated herein for $10 \mu \mathrm{M})$ both endocytosis $\left(37^{\circ} \mathrm{C}\right)$ and translocation $\left(37^{\circ} \mathrm{C}\right.$ and $\left.4^{\circ} \mathrm{C}\right)$ are active internalization pathways. At $37^{\circ} \mathrm{C}$, since Penetratin is less internalized in GAG-deficient cells, its internalization relies on the presence of cell-surface proteoglycans (HS and CS), while the peptide internalized more in cells lacking sialic acids at the cell-surface (SAdef). ns, not significant; * significant; ** very significant.

GAGs are thus essential partners for internalization of many CPPs ${ }^{33}$. Sulfated proteoglycans are located in dynamic transient microdomains enriched in cholesterol and sphingomyelin (SM), and cluster into larger platforms in response to specific stimuli such as ligand binding to membrane receptors. We showed that sphingomyelin hydrolysis (in ceramide) or cholesterol depletion in the cell membrane, affects both translocation and endocytosis ${ }^{34}$, results we explain as follows: i) CPPs can bind and cluster GAGs that act as autonomous receptors and, then follow a specific endocytosis pathway. Alternatively, in the domains from which GAGs are absent, CPPs can recruit and cluster specific membrane lipids, to evoke or stabilize locally, and exploit membrane thinning and defects to translocate. Penetratin for instance shows strong preference for unsaturated phospholipids found in disordered domains as we demonstrated using a photolabeling strategy ${ }^{35}$. The kinetics of a given CPP to partition between cell surface GAGs and in defect regions of the lipid bilayer would determine the balance between endocytosis and translocation pathways of internalization. Of interest is that we could identify that the effects of sphingomyelinase treatment or cholesterol depletion was massive on the entry of Trp-containing CPPs in WT cells, contrasting with the situation in GAG-deficient cells ${ }^{34}$. These results converge with another study in which we demonstrated for the first time that Trp residues in CPPs enhance dramatically the enthalpy of binding of the peptides with HS and CS, and the clustering of GAGs, thus establishing a role of Trp not only interfacial at the level of the lipid bilayer but also crucial at the level of the glycocalyx, involving potential ion-pair $\pi$ interactions ${ }^{32,36}$. Altogether, delineating a general internalization pathway for all CPPs is rather difficult, because CPP sequences differ from one another and can interact with a plethora of molecules at the cell-surface. The current view is that there are two major pathways of internalization : direct translocation across the plasma membrane (transient pore formation, carpet model, inverted micelles etc), and endocytosis that includes bulk (macropinocytosis) and receptor-dependent (clathrin- or caveolin-mediated) processes $5,28,33,36$.

\section{Lack of relationship between membranotropic activity and internalization efficacy of CPPs}

To enter into cells, cationic peptides first interact with membrane components. However, binding of a peptide to the cell membrane is not directly related to its capacity of crossing it. For instance, we have studied two related cationic and secondary amphipathic sequences, RW9 (RRWWRRWRR) and RL9 (RRLLRRLRR). These two peptides have the same number of positive charges, and contain 3 nonpolar residues at the same position in the sequence, either $\mathrm{W}$ or L. The peptide RW937 is internalized twentyfold better than RL9 in cells ${ }^{38}$. But, both peptides bind to the cell membrane, with only a two-fold difference in the quantity of membrane-bound species, that remain after washings, respectively 100 and 250 pmoles for RL9 and RW9. A full analysis of the interaction of the peptides with model membranes underlined a deeper insertion of RL9 compared to RW9 into the lipid bilayer, despite an apparent dissociation constant value of respectively 7.5 and $1.5 \mu \mathrm{M}$ for POPG LUVs ${ }^{39}$. The two peptides have similar affinity for heparin with Kd values of $80 \mathrm{nM}$ (RL9) and $10 \mathrm{nM}$ (RW9) ${ }^{32}$. The fact that a peptide that does not cross the membrane, inserts deeper, is at first glance a counter intuitive result. We further showed that RL9 is retained close to the membrane core region and that this peptide tends to increase lipid ordering around itself. This observation supports the lack of membrane crossing of the peptide, since membrane reorganization leading to RL9 crossing the membrane would indeed be energetically extremely unfavorable. Altogether, these results show that membrane binding should not be used to predict the capacity of a peptide to cross cell membranes (Figure 3). 
A

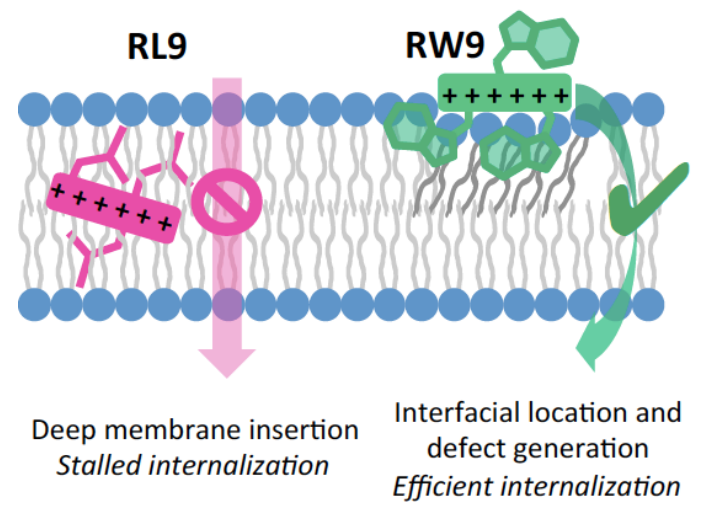

B

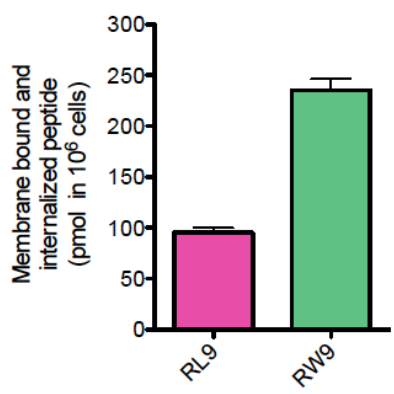

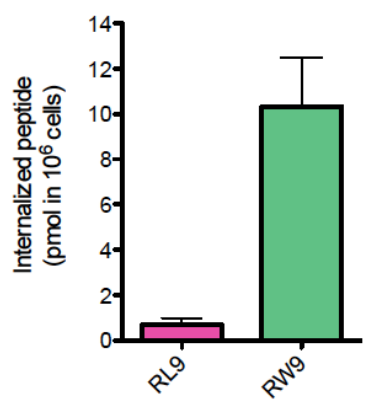

Figure 3- The absence of relationship between membrane binding and cell-penetration activity is illustrated with two amphipathic peptides. A) RL9 binds to the lipid bilayer, inserts deeply within the acyl chains and fails to cross the membrane; RW9 binds to the lipid bilayer at the water/lipid interface and has efficient membrane translocation function ${ }^{39}$. B) MS quantification of cell-associated (membrane-bound and internalized) or internalized peptides ${ }^{39}$.

Other experimental evidences reinforce this assumption. As mentioned above, it is possible to quantify the peptides that remain associated to cells after washings, which includes the membrane-bound and the internalized species ${ }^{40}$. We have shown that the membrane-bound peptide fraction, which is not washable, generally represents from 5 - up to more than 100-folds the internalized peptide fraction. As long as the peptides are sensitive to enzymatic cleavage, it is possible to remove this membrane-bound species for example by trypsin $\left(37^{\circ} \mathrm{C}\right)$ or pronase $\left(4^{\circ} \mathrm{C}\right)$ treatment of cells, leaving for quantification only the internalized fraction of peptide ${ }^{40,30}$. Using this method, we could stress for different CPP sequences (Tat, R9, RW9, Penetratin etc) that their accumulation and binding at the cell-surface do not reflect their internalization efficacy 40,30 . For instance, after $1 \mathrm{~h}$ incubation followed by washings, Penetratin remains associated to similar extent to wild-type (240 pmoles), (HS and CS) GAG-deficient (220 pmoles) and sialic acid- (SA) deficient (360 pmoles) cells, albeit its internalization efficacy strongly differs (respectively 5 , 2.5 and 6.5 pmoles) in the three cell lines ${ }^{30,31}$. These results obtained with these cell lines having different membrane composition, further suggest that the non-washable fraction of peptides is retained at the level of the lipid bilayer. This observation is similar at $37^{\circ} \mathrm{C}$ and $4^{\circ} \mathrm{C}$, although for some CPPs the quantity of membrane-bound species can be higher at $4^{\circ} \mathrm{C}$, likely because the membrane is less fluid and has decreased conformational freedom and dynamics: some membrane-bound peptides would then be even less washable than at $37^{\circ} \mathrm{C}$.

\section{Thermodynamics and kinetics of peptide binding to cell membrane}

The fact that the non-washable membrane-bound fraction of peptides is found at the level of the lipid bilayer questions the thermodynamics and kinetics of the system. Indeed, it has long been reported unequivocally by different groups, including ours, that CPPs have more favorable binding thermodynamics, about one order of magnitude, for highly sulfated polysaccharides compared to any type of phospholipid, even negatively charged ${ }^{41,31,32}$. The binding affinity is indeed generally in the nM range for negatively charged polysaccharides and in the $\mu \mathrm{M}$ range for phospholipids (Figure 4).

We used cell-derived membranes to confirm the latter observation obtained with model membranes ${ }^{31}$. Penetratin has a dissociation constant of $10 \mathrm{nM}$ for WT cell membrane. Its affinity is decreased for GAG-deficient cell membrane with a Kd value of $2 \mu \mathrm{M}$. Interestingly, the Kd value is $200 \mathrm{nM}$ for SA-deficient cells, in which $(10 \mu \mathrm{M})$ Penetratin internalizes better compared to WT cells. Moreover, the dissociation constant for WT cell membrane is very close to the one for heparin and CS, while the Kd for GAG-deficient cell membrane is closer to the one for phospholipids ${ }^{42}$. In addition, the thermodynamics of Penetratin interaction with model membranes of Egg PC/DOPE (1:1) is similar to the one of Egg PC/POPG $(1: 1)^{31}$. Therefore, binding of Penetratin to the lipid bilayer does not only rely on Coulombic interactions, the shape of the lipid headgroup and/or the membrane curvature in PE-enriched membrane domains also have a major contribution. We could confirm this assumption using photolabeling of PC phospholipids with which Penetratin interacts at the level of the lipid/water interface ${ }^{35}$. 
In terms of kinetics, Penetratin binds similarly to the membrane of the three cell types ${ }^{30}$, with a $\mathrm{k}_{\text {on }}$ value of $10^{4} \mathrm{M}^{-1} \mathrm{~S}^{-1} 31,42$, showing that the presence of anionic GAGs does not prevent the cationic peptide from interacting at the level of the lipid bilayer, despite the differences in the affinity of the peptide for the three cell membranes $\left(\mathrm{Kd}=\mathrm{k}_{\text {off }} / \mathrm{k}_{\mathrm{on}}\right)$, respectively $0.01,0.2$ and $2 \mu \mathrm{M}$ for WT, SA-deficient and GAG-deficient cells. This result implies that dissociation kinetic constants are much faster for membranes lacking GAGs than for membranes containing GAGs at their surface. Penetratin indeed dissociates 200-fold faster from the surface of GAG-deficient cells than from the surface of WT cells ${ }^{31,42}$. Furthermore, these dissociation kinetic constants are similar between GAG-deficient cells and lipid model membranes, suggesting that the high dynamics of peptide/lipid complexes is a key step for translocation across the lipid bilayer. Altogether, these results again demonstrate that membrane binding and thermodynamics alone do not reflect the internalization capacity of CPPs. Thermodynamics would favor GAG-dependent internalization pathway, while kinetics reveal the dynamical interaction between CPPs and lipids and favor translocation. Internalization of a CPP is thus a subtle balance between these two pathways.

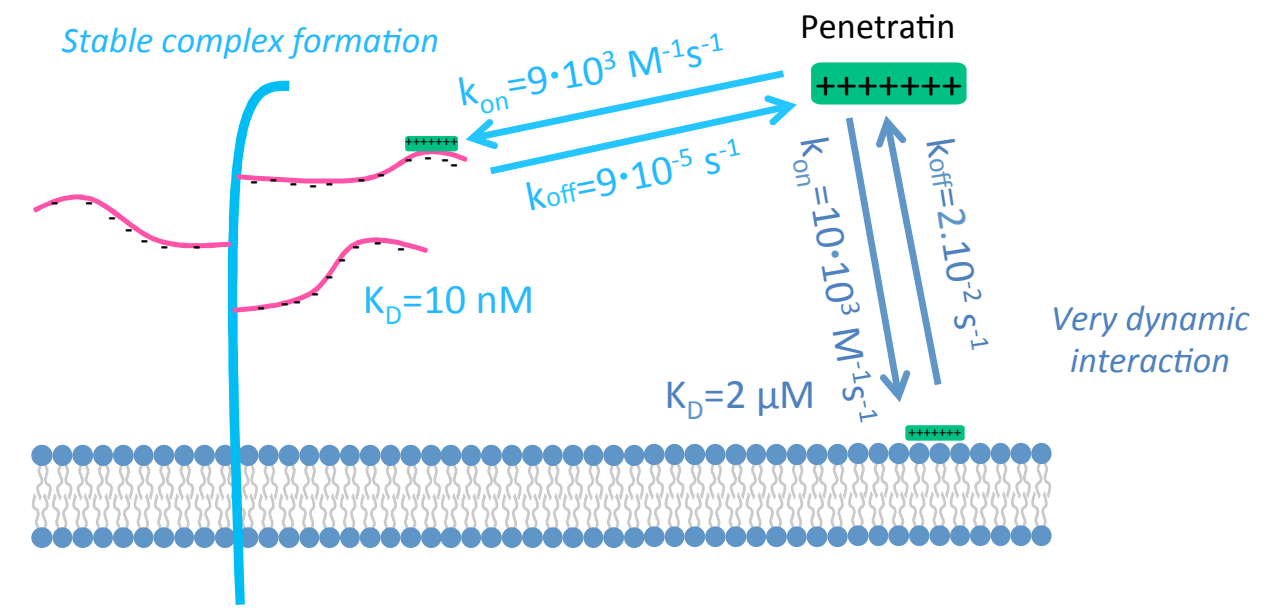

Figure 4 - Thermodynamics favor interaction of Penetratin with anionic GAGs, while kinetics favor its interaction with the lipid bilayer. Data obtained by plasmon waveguide resonance spectroscopy ${ }^{31}$.

Translocation is the first internalization pathway in motion (at low extracellular CPP concentrations). With increasing concentrations of peptide, its accumulation on GAGs at the cell-surface leads to clusters of proteoglycans and endocytosis ${ }^{14,43}$. Because the quantity of membrane-bound peptide always dominates the internalized one, caution should be taken when studying CPP entry, to ensure the complete elimination or the accurate determination of the membrane-bound or -trapped fraction of the peptide. We have contributed to this latter experimental aspect, developing reliable and robust methods to quantify membrane-bound and/or peptides internalized in cells.

\section{Methods to study membrane-trapped or internalized CPPs: optimization and pitfalls}

With the advent of the field of cell-penetrating peptides, came indeed the question of detection of peptides inside cells. More than ten years ago, we developed a method based on MALDI-TOF mass spectrometry (MS) to measure absolute quantities of peptides inside cells. Since this protocol has been reviewed several times ${ }^{44,19,45}$, we just give a brief overview herein. Two identical peptide sequences are synthesized with a biotin-bait in a spacer arm, which is or not isotopically labeled at the $N$-terminal of the sequence. Biotin slightly increases the hydrophobicity of the peptide but allows selective extraction of the peptides after cell lysis and the isotope labeled (deuterium) peptide is used as an internal standard for MS quantification. Briefly, after incubation of a controlled number of cells (generally one million) with the CPP, cells are washed. The membrane-bound peptide is kept intact when cells are only extensively washed with culture medium, and can be removed by enzymatic degradation (trypsin at $37^{\circ} \mathrm{C}$ and pronase at $4^{\circ} \mathrm{C}$ ). Cells are lyzed with a high salt detergent solution containing a relevant amount of the isotope labeled version of the same CPP. The two peptides are then captured from lyzed cells on streptavidin-coated magnetic beads. After drastic washings (high salt, SDS etc) of the beads, elution of the peptides is obtained at acid $\mathrm{pH}$ with the MALDI matrix $\alpha$-cyano-4-hydroxycinnamic acid. The absolute amount of the internalized CPP is calculated from the ratio of the unlabeled and labeled isotope massif of the CPP in the mass spectra. This robust method has proven very helpful to quantify membrane-bound internalized 
peptide amounts, to study the mechanisms of internalization of CPPs, as well as their transport efficacy by quantifying directly a conjugated cargo peptide $46,47,18,37$. In addition this method allows the analysis of the intracellular degradation of the CPPs or peptide cargoes. Interestingly, we have found CPPs such as Tat, Penetratin, R9 and RW9 to be stable inside cells within a few hours incubation, since, the most abundantly detected species corresponds to the intact peptide ${ }^{19,37,40}$. A modified analogue of RW9 allowed us to determine that the intact peptide represents $60 \%$ of the ion species detected after $1 \mathrm{~h} 15$ incubation and $30 \%$ after 18 hours $^{37}$.

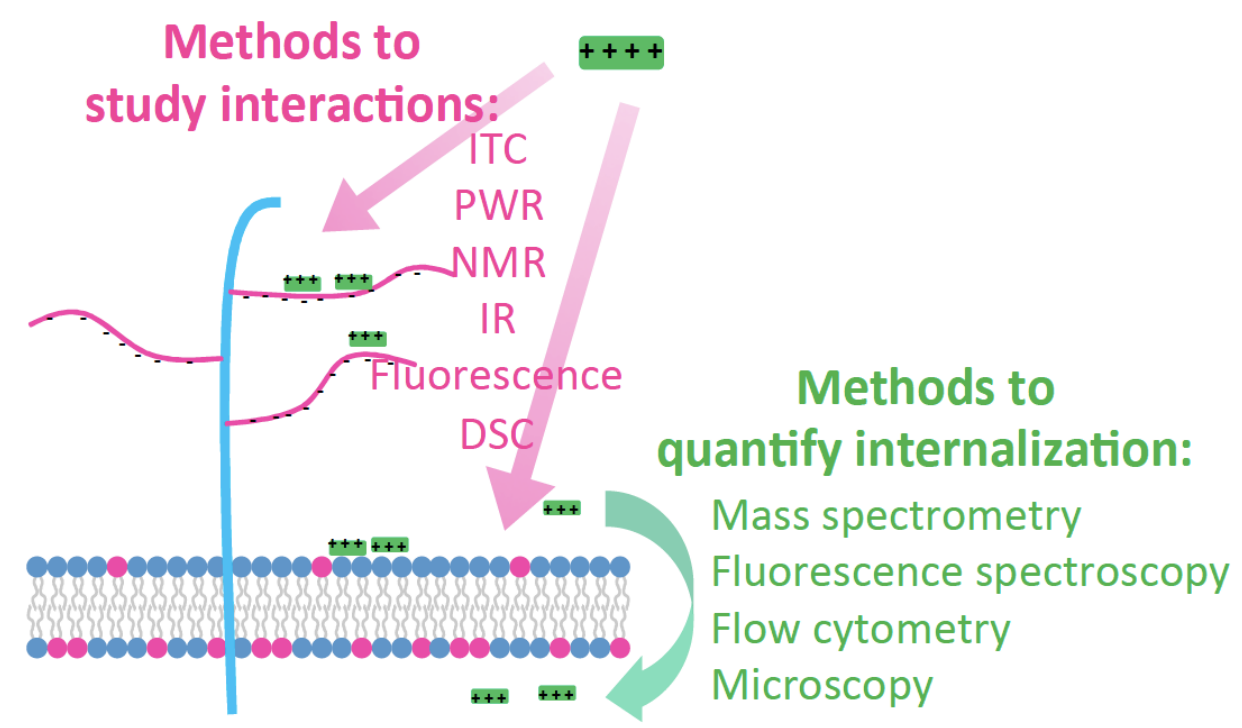

Figure 5 - Current methods used to study peptide interaction with membranes or internalization in cells. ITC, isothermal calorimetry; DSC, differential scanning calorimetry; NMR, nuclear magnetic resonance spectroscopy; IR, infrared spectroscopy.

Fluorescence currently remains the most used method to detect peptides in cells, either by fluorescence imaging or flow cytometry. We evaluated the robustness and reliability of cytometry for the quantification of CPPs in cells and proposed an optimized method based on fluorometry allowing absolute quantification. As a premise, we have to note that the presence of a fluorescent label can in some cases shift the cytotoxicity of CPPs to lower concentrations. This is not surprising since these dyes are generally large and hydrophobic. In fact, fluorescent dyes may increase the molar mass of these short peptides by a mass corresponding to that of 3 (for fluorescein), 5 (for rhodamine) or even more amino acids. For example, as mentioned above, the nonapeptide RL9 is hardly internalized in CHO cells and has no cytotoxicity up to $20 \mu \mathrm{M}^{38,48}$. In contrast, the Alexa-488 labeled RL9 is already cytotoxic at low $\mu \mathrm{M}$ concentrations. When the fluorescent peptide is incubated at a concentration slightly cytotoxic, it can be observed inside cells and model giant vesicles. When the concentration is reduced to non-cytotoxic one, the peptide is no longer detected in cells, showing that the use of fluorescent peptides can give way to false positive results in internalization studies. In addition, depending on its anchoring position on the peptide, the fluorescent dye can more or less affect the efficiency of CPP entry ${ }^{49}$.

We demonstrated that absolute quantification of internalized CPPs is also possible by fluorometry, using a protocol similar to the one established for MS quantification ${ }^{49}$ : membrane-bound peptide is removed by protease treatment and cell are lyzed before measuring peptide amounts in both cases $^{49}$. Although the two techniques are totally different, results obtained by fluorometry and by mass spectrometry converge, for different cell lines and peptide sequences. Relative quantification by flow cytometry also merge with those obtained by fluorometry and mass spectrometry, but in a restricted range of peptide to cell ratio. This was not unexpected since the protocols used for mass spectrometry and fluorometry techniques are destructive for cells, and allow the accurate detection of the totality of the internalized peptide. In particular, in the case of fluorometry, the full fluorescence signal is recovered after cell lysis (absence of fluorescence quenching, controlled $\mathrm{pH}$ for prototropic and solvatochromic dyes, such as fluorescein). In contrast, flow cytometry, a non-intrusive technique like fluorescence imaging, is limited by the cell structure and organization: quenching processes and formation of non-fluorescent peptide species can indeed occur in the cell membrane and inside cells. For all techniques, we recommend to run in parallel cytotoxicity assays and when using flow cytometry to quantify fluorescent CPP internalization, 
to test different peptide/cell ratios for consistency, to ensure the complete removal of membrane-bound species, and to consider potential quenching processes and formation of non-fluorescent peptide species (formation of aggregates, acidic $\mathrm{pH})^{49}$.

\section{Future direction - lessons from homeoproteins}

We described methods (Figure 5) and the complex study of membrane crossing of cellpenetrating peptides, a question that remains open in the field. One particular point we have not discussed in this Account relates to the lack of selective entry of CPPs in cells. This is obviously not the case for example for homeoproteins, these highly specialized transcription factors that transfer from cell to cell. Some homeoproteins show for instance selective entry into specific neuronal cells in the central nervous system of animals ${ }^{51}$. Since these proteins include very specialized and independent peptide domains with defined functions, we should take advantage of those to identify protein domains, that would help CPPs to target specifically cell-surface molecules and enhance their selectivity.

\section{Biographical information}

Dr. Astrid Walrant obtained her Ph. D. in Chemistry in 2011 from the Université P. et M. Curie (Paris, France). She then joined the group of Jenny Gallop, at the Gurdon Institute and Biochemistry Department, University of Cambridge, (UK) as a postdoctoral researcher. She joined the Université P. et M. Curie as an Assistant Professor in 2014, at the Chemistry Department. Her research focuses on the analysis of the interactions of membrane active peptides and proteins with model and biological membranes.

Dr. Sébastien Cardon obtained two M.Sc. one in Organic Chemistry (2013) from the Université P. et M. Curie, and one in Biology (2014) from the Université Paris Diderot. During his masters, he worked on structure-activity relationships of antimicrobial peptides with Dr. Claire Lacombe, and on the residues involved in the selective transfer properties of the model enzyme FemXw with Dr. Matthieu Fonvielle. In October 2017, he obtained his Ph.D. on the specific role of GAGs on the structure and internalization properties of the homeoprotein Engrailed 2, under the supervision of Dr. Sandrine Sagan and Dr. Ludovic Carlier.

Dr. Fabienne Burlina obtained her Ph. D. in Chemistry in 1996 from the Université de Paris Sud (France). She then joined the group of M. J. Gait at the LMB (Cambridge, UK) as a post-doctoral fellow. Since 1999, she works in the Chemistry Department of the Université P. et M. Curie (Paris, France) as a CNRS researcher. Her current research focuses on the design and study of cell-penetrating peptides for the delivery of bioactive compounds. She is also interested in the development of ligation methodologies for the synthesis of bio-conjugates and proteins.

Dr. Sandrine Sagan obtained her Ph.D. (1991) in Molecular and Cellular Pharmacology from the Université P. et M. Curie (UPMC), Paris (France), at the Institut Jacques Monod. She pursued as a postdoctoral fellow at Salzburg research institute (Austria). In 1993, she joined the Chemistry Department of UPMC, where she is now heading a laboratory as a CNRS senior researcher. She has contributed structure-activity relationships in opioid, cannabinoid and tachykinin systems, photolabeling and mass spectrometry of membrane proteins, and is currently focused on the comprehensive analysis of the molecular mechanisms of entry of cell-penetrating peptides.

\section{References}

1. Green, M.; Ishino, M.; Loewenstein, P.M. Mutational analysis of HIV-1 Tat minimal domain peptides: identification of trans-dominant mutants that suppress HIV-LTR-driven gene expression. Cell. 1989, 58, 215-223.

2. Vivès, E.; Brodin, P.; Lebleu, B. A truncated HIV-1 Tat protein basic domain rapidly translocates through the plasma membrane and accumulates in the cell nucleus. J. Biol. Chem. 1997, 272, 16010-16017.

3. Joliot, A.H.; Triller, A.; Volovitch, M.; Pernelle, C.; Prochiantz, A. Alpha-2,8-Polysialic acid is the neuronal surface receptor of antennapedia homeobox peptide. New Biol. 1991, 3, 1121-1134. 
4. Derossi, D.; Joliot, A.H; Chassaing, G.; Prochiantz, A. The third helix of the Antennapedia homeodomain translocates through biological membranes. J. Biol. Chem. 1994, 269, 1044410450.

5. Copolovici, D.M.; Langel, K.; Eriste, E.; Langel, Ü. Cell-penetrating peptides: design, synthesis, and applications. ACS Nano. 2014, 8, 1972-1994.

6. Ruoslahti, E. Tumor penetrating peptides for improved drug delivery. Adv. Drug Del. Rev. 2017, 110, 3-12.

7. Eiríksdóttir, E.; Konate, K.; Langel, Ü.; Divita, G.; Deshayes, S. Secondary structure of cellpenetrating peptides controls membrane interaction and insertion. Biochim. Biophys. Acta. 2010, 1798, 1119-1128.

8. Bechara, C.; Pallerla, M.; Zaltsman, Y.; Burlina, F.; Alves, I.D.; Lequin, O.; Sagan, S. Tryptophan within basic peptide sequences triggers glycosaminoglycan-dependent endocytosis. FASEB J. 2013, 27, 738-749.

9. Bayer, P.; Kraft, M.; Ejchart, A.; Westendorp, M.; Frank, R.; Rösch, P. Structural studies of HIV-1 Tat protein. J. Mol. Biol. 1995, 247, 529-535.

10. Magzoub, M.; Eriksson, L.E.; Gräslund, A. Conformational states of the cell-penetrating peptide penetratin when interacting with phospholipid vesicles: effects of surface charge and peptide concentration. Biochim. Biophys. Acta. 2002, 1563, 53-63.

11. Esko, J.D.; Kimata, K.; Lindahl, U. Proteoglycans and sulfated glycosaminoglycans. In Essentials of Glycobiology; Varki, A., Cummings, R.D., Esko, J.D., Freeze, H.H., Stanley, P., Bertozzi, C.R., Hart, G.W., Etzler, M.E., Eds. 2nd edition. Cold Spring Harbor (NY): Cold Spring Harbor Laboratory Press, 2009; Chapter 16.

12. Iozzo, R.V. Turnover of heparan sulfate proteoglycan in human colon carcinoma cells. A quantitative biochemical and autoradiographic study. J. Biol. Chem. 1987, 262, 1888-1900.

13. van Meer G.; Voelker, D.R.; Feigenson, G.W. Membrane lipids: where they are and how they behave. Nat. Rev. Mol. Cell Biol. 2008, 9, 112-124.

14. Tkachenko, E.; Simons, M. Clustering induces redistribution of syndecan-4 core protein into raft membrane domains. J. Biol. Chem. 2002, 277, 19946-19951.

15. Binch, A.L.A.; Shapiro, I.M.; Risbud, M.V. Syndecan-4 in intervertebral disc and cartilage: Saint or synner? Matrix Biol. 2016, 52-54, 355-362.

16. Cullis, P.R.; De Kruijff, B. Lipid polymorphism and the functional roles of lipids in biological membranes. Biochim. Biophys. Acta 1979, 559, 399-420.

17. Mills, J.T., Furlong, S.T., Dawidowicz, E.A. Plasma membrane biogenesis in eukaryotic cells: translocation of newly synthesized lipid. Proc. Natl. Acad. Sci. U.S.A. 1984, 81, 1385-1388.

18. Aubry, S.; Burlina, F.; Dupont, E.; Delaroche, D.; Joliot, A.; Lavielle, S.; Chassaing, G.; Sagan, S. Cellsurface thiols affect cell entry of disulfide-conjugated peptides. FASEB J. 2009, 23, 2956-2967.

19. Aubry, S.; Aussedat, B.; Delaroche, D.; Jiao, C.Y.; Bolbach, G.; Lavielle, S.; Chassaing, G.; Sagan, S.; Burlina, F. MALDI-TOF mass spectrometry: a powerful tool to study the internalization of cellpenetrating peptides. Biochim. Biophys. Acta. 2010, 1798, 2182-2189.

20. Emi, N.; Kidoaki, S.; Yoshikawa, K.; Saito, H. Gene transfer mediated by polyarginine requires a formation of big carrier-complex of DNA aggregate. Biochem. Biophys. Res. Commun. 1997, 231, 421-424.

21. Mitchell, D.J.; Kim, D.T.; Steinman, L.; Fathman, C.G.; Rothbard, J.B. Polyarginine enters cells more efficiently than other polycationic homopolymers. J. Pept. Res. 2000, 56, 318-325.

22. Futaki, S.; Suzuki, T.; Ohashi, W.; Yagami, T.; Tanaka, S.; Ueda, K.; Sugiura, Y. Arginine-rich peptides. An abundant source of membrane-permeable peptides having potential as carriers for intracellular protein delivery. J. Biol. Chem. 2001, 276, 5836-5840.

23. Sakai, N.; Matile, S. Anion-mediated transfer of polyarginine across liquid and bilayer membranes. J. Am. Chem. Soc. 2003, 125, 14348-14356.

24. Rothbard, J.B.; Jessop, T.C.; Lewis, R.S.; Murray, B.A.; Wender, P.A. Role of membrane potential and hydrogen bonding in the mechanism of translocation of guanidinium-rich peptides into cells. J. Am. Chem. Soc. 2004, 126, 9506-9507.

25. Palm-Apergi, C.; Lorents, A.; Padari, K.; Pooga, M.; Hällbrink, M. The membrane repair response masks membrane disturbances caused by cell-penetrating peptide uptake. FASEB J. 2009, 23, 214-223.

26. Berlose, J.P.; Convert, O.; Derossi, D.; Brunissen, A.; Chassaing, G. Conformational and associative behaviours of the third helix of antennapedia homeodomain in membrane-mimetic environments. Eur. J. Biochem. 1996, 242, 372-386. 
27. Wadia, J.S.; Stan, R.V.; Dowdy, S.F. Transducible TAT-HA fusogenic peptide enhances escape of TAT-fusion proteins after lipid raft macropinocytosis. Nat. Med. 2004, 10, 310-315.

28. Dunn, W.A.; Hubbard, A.L.; Aronson, N.N. Low-temperature selectively inhibits fusion between pinocytic vesicles and lysosomes during heterophagy of asialofetuin-i-125 by the perfused-ratliver. J. Biol. Chem. 1980, 255, 5971-5978.

29. Vercauteren, D.; Vandenbroucke, R.E.; Jones, A.T.; Rejman, J.; Demeester, J.; De Smedt, S.C.; Sanders, N.N.; Braeckmans, K. The use of inhibitors to study endocytic pathways of gene carriers: optimization and pitfalls. Mol. Ther. 2010, 18, 561-569.

30. Jiao, C.Y.; Delaroche, D.; Burlina, F.; Alves, I.D.; Chassaing, G.; Sagan, S. Translocation and endocytosis for cell-penetrating peptide internalization. J. Biol. Chem. 2009, 284, 33957-33965.

31. Alves, I.D.; Bechara, C.; Walrant, A.; Zaltsman, Y.; Jiao, C.Y.; Sagan, S. Relationships between membrane binding, affinity and cell internalization efficacy of a cell-penetrating peptide: penetratin as a case study. PLoS One. 2011;6(9):e24096.

32. Bechara, C.; Pallerla, M.; Zaltsman, Y.; Burlina, F.; Alves, I.D.; Lequin, O.; Sagan, S. Tryptophan within basic peptide sequences triggers glycosaminoglycan-dependent endocytosis. FASEB J. 2013, 27, 738-749.

33. Favretto, M.E.; Wallbrecher, R.; Schmidt, S.; van de Putte, R.; Brock, R. Glycosaminoglycans in the cellular uptake of drug delivery vectors - bystanders or active players? J. Control. Release. 2014, 180, 81-90.

34. Bechara, C.; Pallerla, M.; Burlina, F.; Illien, F.; Cribier, S.; Sagan, S. Massive glycosaminoglycandependent entry of Trp-containing cell-penetrating peptides induced by exogenous sphingomyelinase or cholesterol depletion. Cell. Mol. Life Sci. 2015, 72(4):809-820.

35. Jiao, C.Y.; Sachon, E.; Alves, I.D.; Chassaing, G.; Bolbach, G.; Sagan, S. Exploiting benzophenone photoreactivity to probe the phospholipid environment and insertion depth of the cellpenetrating peptide Penetratin in model membranes. Angew. Chem. Int. Ed. Engl. 2017, 56, 82268230.

36. Bechara, C.; Sagan S. Cell-penetrating peptides: 20 years later, where do we stand? FEBS Lett. 2013, 587, 1693-1702.

37. Delaroche, D.; Aussedat, B.; Aubry, S.; Chassaing, G.; Burlina, F.; Clodic, G.; Bolbach, G.; Lavielle, S.; Sagan, S. Tracking a new cell-penetrating (W/R) nonapeptide, through an enzyme-stable mass spectrometry reporter tag. Anal. Chem. 2007, 79, 1932-1938.

38. Walrant, A.; Correia, I.; Jiao, C.Y.; Lequin, O.; Bent, E.H.; Goasdoué, N.; Lacombe, C.; Chassaing, G.; Sagan, S.; Alves, I.D. Different membrane behaviour and cellular uptake of three basic argininerich peptides. Biochim. Biophys. Acta. 2011, 1808, 382-393.

39. Walrant, A.; Vogel, A.; Correia, I.; Lequin, O.; Olausson, B.E.; Desbat, B.; Sagan, S.; Alves, I.D. Membrane interactions of two arginine-rich peptides with different cell internalization capacities. Biochim. Biophys. Acta. 2012, 1818, 1755-1763.

40. Burlina, F.; Sagan, S.; Bolbach, G.; Chassaing, G. Quantification of the cellular uptake of cellpenetrating peptides by MALDI-TOF mass spectrometry. Angew. Chem. Int. Ed. Engl. 2005, 44, 4244-4247.

41. Gonçalves, E;. Kitas, E.; Seelig, J. Binding of oligoarginine to membrane lipids and heparan sulfate: structural and thermodynamic characterization of a cell-penetrating peptide. Biochemistry. 2005, 44, 2692-2702.

42. Sagan, S.; Burlina, F.; Alves, I.D.; Bechara, C.; Dupont, E.; Joliot, A. Homeoproteins and homeoprotein-derived peptides: going in and out. Curr. Pharm. Des. 2013, 19, 2851-2862.

43. Christianson, H.C.; Belting, M. Heparan sulfate proteoglycan as a cell-surface endocytosis receptor. Matrix Biol. 2014, 35, 51-55.

44. Burlina, F.; Sagan, S.; Bolbach, G.; Chassaing, G. A direct approach to quantification of the cellular uptake of cell-penetrating peptides using MALDI-TOF mass spectrometry. Nat. Protoc. 2006, 1, 200-205.

45. Sagan, S.; Bechara, C.; Burlina, F. Study of CPP Mechanisms by Mass Spectrometry. Methods Mol. Biol. 2015, 1324, 107-121.

46. Aussedat, B.; Dupont, E.; Sagan, S.; Joliot, A.; Lavielle, S.; Chassaing, G.; Burlina, F. Modifications in the chemical structure of Trojan carriers: impact on cargo delivery. Chem. Commun. (Camb). 2008, 12, 1398-1400.

47. Bode, S.A.; Thévenin, M.; Bechara, C.; Sagan, S.; Bregant, S.; Lavielle, S.; Chassaing, G.; Burlina, F. Self-assembling mini cell-penetrating peptides enter by both direct translocation and glycosaminoglycan-dependent endocytosis. Chem. Commun. (Camb). 2012, 48, 7179-7181. 
48. Walrant, A.; Matheron, L.; Cribier, S.; Chaignepain, S.; Jobin, M.L.; Sagan, S.; Alves, ID. Direct translocation of cell-penetrating peptides in liposomes: a combined mass spectrometry quantification and fluorescence detection study. Anal. Biochem. 2013, 438, 1-10.

49. Illien, F.; Rodriguez, N.; Amoura, M.; Joliot, A.; Pallerla, M.; Cribier, S.; Burlina, F.; Sagan, S. Quantitative fluorescence spectroscopy and flow cytometry analyses of cell-penetrating peptides internalization pathways: optimization, pitfalls, comparison with mass spectrometry quantification. Sci. Rep. 2016, 6, 36938.

50. Kauffman, W.B.; Fuselier, T.; He, J.; Wimley, W.C. Mechanism Matters: A Taxonomy of Cell Penetrating Peptides. Trends Biochem Sci. 2015, 40, 749-764.

51. Beurdeley, M.; Spatazza, J.; Lee, H.H.; Sugiyama, S.; Bernard, C.; Di Nardo, A.A.; Hensch, T.K.; Prochiantz, A. Otx2 binding to perineuronal nets persistently regulates plasticity in the mature visual cortex. J. Neurosci. 2012, 32, 9429-9437. 